\title{
Introduction: Telos, Culture, and Enhancement Technologies
}

\author{
Michael C. Brannigan
}

Published online: 15 September 2012

(C) Springer Science+Business Media, LLC 2012

This remarkably unique gathering of perspectives gives testimony to the intricate complexity of enhancement technologies. Each author writes from his and her rich background and expertise. And while their backgrounds are unique-Medical Ethicist in Pittsburgh, Stanford Law and Biosciences Fellow, Philosopher in Indiana, Norwegian Social Researcher, and an Ethicist for UNESCO in Bangkokthey share common ground in viewing moral matters in enhancement through the lens of culture and teleology. I remain grateful to each of them for sharing with us their invaluable insights and for challenging us to dig deeper, beneath the surface of conventional bioethics discourse, urging us to pursue questions that, more than ever in this time of unheralded individualism and biomedical consumerism, need to be pursued. Of course, this issue would not have seen light without the encouragement and support of Andrew Edgar. His wise counsel and infinite patience have kept me on track. I extend to Andrew my genuine and steadfast gratitude.

This special issue in Health Care Analysis pursues the theme of enhancement technologies, particularly in view of both cultural worldviews and perspectives here in the U.S. and beyond, in Norway and Asian countries. The December 17, 2008 near-total face transplant for a woman at the Cleveland Clinic illustrates medical restoration as a more global phenomenon. The patient, with facial trauma so severe that she lacked a nose and palate as well as the ability to breathe on her own, had $80 \%$ of her face replaced from a female cadaver. Earlier partial face transplants occurred in France and China. Though this case clearly represents medical necessity, the procedure raises the specter of enhancement technologies, defined broadly as "externally applied procedures aimed at improving human appearance, behaviors, or capacities." Vigorous debate persists as to whether enhancement technologies offer more promise or peril. In view of this debate, cultural beliefs and

M. C. Brannigan ( $\bowtie)$

Department of Philosophy and Religious Studies, The College of Saint Rose, 432 Western Avenue, Albany, NY 12203, USA

e-mail: michael.brannigan@strose.edu 
values raise questions about what makes us human, what comprises "self," and what constitutes virtue. This issue explores some of the more prevailing and significant cultural perspectives on enhancement technologies. Furthermore, how do policies and guidelines concerning enhancement technologies reflect cultural guiding values and principles? No doubt, the impact of the importation of Western enhancement technique by necessity spurs on further assessment of globalization in matters of healthcare.

Contours of the ethical issues are usually framed in terms of for and against. Entrenched opposition to enhancement technologies highlights, for example, the added potential for discrimination against vulnerable populations (the poor, disabled, people of color, and women). For this reason, Francis Fukuyama in Our Posthuman Future asserts the need for global policies that limit research and development of enhancement technologies. The President's Commission on Bioethics in the U.S. argues likewise in its Beyond Therapy, compelled by concerns of human reproductive cloning research.

In contrast, defenders underscore the centrality of persons' moral right to control their bodies, behaviors, and forms of reproduction. Supporters also emphasize individual as well as professional research liberties. Ramez Naam's More than Human delivers a pragmatic justification of sustained enhanced technology research, development, and implementation.

As we will see in these instructive essays, enhancement technologies, whether medically-related or purely cosmetic, resurrect questions regarding personal identity, bodiliness, and self. Altering physical, intellectual, and behavioral capacities raises a broad array of ethical questions. In what ways do enhancement technologies pose limits to individual rights and freedoms? How can countries ensure equitable distribution of benefits? Are there moral and cultural limits to the use of pharmacological agents and gene technologies to augment intellectual capacity and memory? Would genetic manipulation to modify and 'improve' human behavior affect cultural understandings of individual effort and merit in athletic competition? Our authors challenge us with these far-reaching questions.

Upon the heels of this past summer's Olympics in London, it is fitting that we begin with Lisa Parker's timely analysis. What is especially appealing about the Olympics is their reminder to us of social contingencies within which individual athletes exert their individual struggles, efforts which Parker reveals as not solely private but the result of various social factors. Her engaging analysis works from broader concerns of justice and fairness to the more concentrated matter of individual effort and merit, underscoring the subtle yet powerful role of the social dynamic behind personal achievement.

The more dramatic implications of genetic enhancement in sports compel us to revisit key questions: What constitutes unfair advantage? And what is meant by excellence? Furthermore, what does it mean to claim that an athlete is "deserving"? What is the relationship, less explored by bioethicists, between effort and just reward? In spotlighting individual effort, Parker also challenges us to rethink our own role in the domain of social responsibility.

Her highly informative overview of existing enhancement technologies sets the stage for exposing certain problems that occur when treating also involves 
enhancing. For instance, current gene transfer techniques such as increasing erythropoietin (Epo), though therapeutic, carry the potential to enhance healthy persons. This makes outright bans like the World Anti-Doping Agency's (WADA) absolute prohibition of gene doping for athletes even when treating disorders questionable. Furthermore, if we disallow certain types of athletic enhancement on grounds of harm, then given existing enhancements that are already used and risks already accepted, what risks should we forbid, prevent, minimize, or treat? Policies that ban appear inconsistent with current practices. Is there a substantive difference between biking in high altitudes and using steroids for performance? To be sure, addressing risks may alter not only the nature of the sport itself but that of sports in general. Parker thus takes us into the heart of the matter, raising the question of telos - what is the ultimate aim of sports? What is the true spirit of sport?

At the same time, Parker insightfully explores the question of social justiceWhat constitutes unfair advantage, that edge which is "unfairly gained"? Questions of social justice are complex, particularly in view of the fact that athletic competition, to be meaningful as competition, first celebrates integral inequalities. We celebrate victories. Indeed, we see this in football commercials touting the next Super Bowl champion even before the season starts. For us Americans, at least, it is all about winning. Yet athletic competition ideally occurs within a context of moral equality.

Parker applies features of distributive justice in sports through focusing more on the idea of individual effort, which is normally the center of public attention as well as fodder for media-individual athletes and superstars in moments of triumph and defeat. Her close inspection of individual effort unveils a web of social geography beyond the individual's control, yet with which the individual operates. For instance, we tend to compartmentalize individual achievement as self-willed, within the control of the individual. Yet, expressions of self-will occur within a web of subtle though powerful relationships-socio-economic, familial, peers, social environment-all subject to the social lottery. Though we, often rightfully, celebrate those who struggle against all odds, the power of those unspoken factors can be positive or deleterious. In bringing these hidden factors to our attention, Parker's telling statement that "it may take less courage to be courageous" reaches into a core, unexplored question as to what does it truly mean to be "deserving" of award or recognition? When we say "She deserves it," the prime candidate for just desert usually rests upon hard work and willpower. But hard work and willpower operate within a social context.

Parker thereby challenges the prevailing model of athletic achievement which recognizes and rewards the individual based purely upon his or her individual qualities as individual. This model does little justice to both the bigger picture as well as to the individual herself. Furthermore, recognizing sports within the context of social justice induces us to consider our own role and responsibility with respect to this social geography. While social geography may be certainly beyond individual control, much of this social lottery hinges upon our responsibility, efforts, and engagement. Parker's insights stir our conventional assumptions regarding athletic competition. Her discerning, albeit for many of us uncomfortable, analysis proposes a transformative challenge that we be aware of our complicity in the wider 
context. Her call to action beckons us to challenge our cultural ethos of iconized individualism.

Next, Matt Lamkin nicely explores how the idea itself of athletic competition can also be misapplied. With an alarming number of students on "study drugs" like Ritalin and Adderall, whose purpose is to treat, not to enhance, he raises crucial questions on a number of levels.

To begin with, regarding arguments that these enhancements pose an unfair advantage for students who choose to use these, does this constitute a form of cheating, similar to steroid use by athletes? Critics charge these drugs constitute unfair competition in the setting of learning where there should be a level playing field. As with Lisa Parker, the operative term lies in the "unfairness" of the advantage. In the wake of strict prohibitive measures in some universities to ban such drugs, Lamkin suspects whether these policies actually work. Instead, he argues, they constitute part of the problem.

Moreover, considering the technologies themselves as the culprit provokes us to devise policies that ban their use. (This is similar to Patrick Kermit's worry later on about fixating on the cochlear implant without considering its wider use.) This "quick fix" offers no long-term solution and may indeed be ineffectual as well as counterproductive. And the argument that cognitive enhancement actually cheats the user herself, less so than others, unearths a rich source of discomfort. Prohibitive measures therefore betray a "misguided assessment" of the real problem-our assumptions regarding the nature and aims of higher education. This is again a question of telos. We mistakenly assume that higher education constitutes a hallowed battleground of stiff competition, similar to organized sports. According to Lamkin, this analogy between sports and formal learning is false.

But Lamkin digs deeper. What accounts for this prevailing view that higher education is about high competition? It derives from imbedded cultural values. Here, Lamkin, like Lisa Parker, calls for a bold cultural transformation. If our cultural ethos drives how we think about higher education, as high-stakes competition, we need to work in ways to redirect our cultural disposition in order to restore education's telos, which is personal and attentive engagement in the learning process itself. Using ideas from Maartje Schermer, who in turn applies Alisdair MacIntyre's typology of external and internal goods, Lamkin points out how, when it comes to education, our culture has heralded external goods of occupation, career, money, material status - that is, "success" —at the cost of minimizing or disregarding the value of internal goods, the richness involved in personal engagement in the learning process, including the development of personal, social, and moral maturity. Particularly in our outcome-oriented (that is, outcome-defined and outcome-determined) society, the problem today is that we've internalized external goods, abandoning any distinction by wrapping all goods under the realm of external.

As for pressures students face to compete in the academy, this is less a matter of outright coercion, but more about degrees of manipulation from public, social, and economic pressures all grounded upon wrong-headed assumptions of education as primarily competitive. Certainly, students, like all of us, face external pressures. However, the real pressures come from within. Again, we internalize these external 
pressures, just as we first grow old in others' eyes thus internalizing their perspectives. Underscoring competitive aspects in education reinforces outcome orientation. The 'better' the grade, or outcome, the better the measure. Therefore, prohibiting learning enhancements only makes the problem worse.

So, the problem lies not in the technologies themselves, but in the ways we use them and how this affects our relationship to them, to ourselves, and to others. In other words, Lamkin admits that students may use study enhancements in order to more fully engage in the learning process, which is different from using them as a "shortcut" to better grades.

Lamkin confidently proposes that we "restructure incentives" to be congruent with the proper telos of education, namely an appreciation of the internal good of engaging in the process of learning. He urges us to reframe what has thus far been a zero-sum, either/or debate, a consequence of focusing on and targeting the technologies themselves apart from their wider contexts. We need to reshape our prevailing cultural ethos of winner-takes-all in the name of competition for external goods, by resurrecting the vital significance of learning's internal richness as attentive engagement and reflection.

With Sandra Shapshay's essay, we return to the more customary enhancement arena of reproductive technologies. Her superb account of inconsistent reasoning in arguments defending and opposing human reproductive cloning reveals a common thread of moral agreement between contrasting parties. She does this through deftly inspecting John Robertson's more liberal argument defending the use of human cloning.

First, she neatly lays out the predictable responses of U.S. bioethicists when confronted with a new technology and its potential conflicts. In somewhat Hegelian strokes, the initial idea with its possible utopic vision gives way to various warnings and dystopic portrayals. Shapshay herself has described earlier more dystopic questions alluding to certain films such as Gattaca, which she incisively explored in her instructive Bioethics at the Movies. These portrayals are eventually met with counter-emphases upon liberty rights and concerns, in the process reinforcing principles of individual rights and freedom. With our culture's "presumptive primacy" of procreative liberty, the onus probandum, or burden of proof, rests upon those who prohibit human cloning if human cloning was shown to be safe.

She then unpacks Robertson's support for human cloning on the grounds of the presumptions regarding the negative right surrounding "procreative liberty." Rather than disarm the various arguments against cloning, which Greg Pence nicely does in his Who's Afraid of Human Cloning?, Shapshay discovers that those arguments defending human cloning under certain conditions, such as Robertson's, actually bear seeds of opposition. In applying a Kantian framework from the start, Shapshay strengthens an a priori moral argument against human cloning, her essential aim. At the same time, her disclosing common ground between the opposing parties is a refreshing move forward in a discipline otherwise glutted with polarization and critique fatigue.

She explores four cases Robertson uses to illustrate his support for human cloning. Despite his overriding support, Robertson does object to human cloning when it spawns commodification, as when children are treated as "fungible 
commodities." Inspecting more closely certain justifying reasons Robertson offers, such as the nebulous notion of intent to rear the cloned child, she points out inconsistencies in his reasoning. Shapshay's use of Margaret Radin's definition of "commodification"- "the social construction of an item as a salable object in an organized market"-is key to her argument. Commodification therefore is not merely an end product but begins to occur in the complex process leading up to it, in which a degree of alienation between the person and salable object becomes increasingly apparent. (I'm reminded here of the earlier Japanese reluctance towards heart transplantation as it involved the separation, and perceived alienation, between the itemized heart and the person. In Japanese traditional culture, the heart plays a vital role in notions of 'self.') In line with Matt Lamkin's analysis of "learning enhancement" technologies, Shapshay stresses the force of societal pressures from all directions so that such pressures enable reproductive technologies, given they are safe, to be in effect "mandatory."

Throughout her account, rather than reifying deontological and utilitarian methodologies, Shapshay grounds her analysis on Kant's argument against treating persons simply as means to an end. No doubt, in our consumerist society based ultimately on product and exchange value, violating Kant's principle denies the child's moral right to an open future. For Shaphsay, Roberston's commodification argument in effect deflates his own prior arguments defending certain instances of human cloning. She suggests that we consider commodification, not as an either/or fact or event, but as the end of a process, on a sliding scale ranging from noninstrumentalization to more problematic instrumentalizing to unjustified commodification. Like Lamkin, Shapshay is especially concerned with the move towards commodification, and she cautions us against the "morally worrisome" move from instrumentalizing persons to commodifying them.

Patrick Kermit offers us an intriguing and insightful look into the noteworthy enhancement technology of cochlear implants, particularly in children, a subject in bioethics debate that has thus far remain polarized with little headway. Though somewhat toned down, the issue remains significant in Scandinavian countries. And through his well-formulated analysis, he especially poses the question again of telos. Namely, what is the aim of these devices? For Kermit, prevailing aims not only to restore a sense of sound but to bring about facility in spoken communication, speaking as the normative standard, appear unrealistic and unfair, skewed under the questionable measuring notion of "normalization."

First, he nicely situates cochlear implants within the context of their tremendous benefit beyond simple amplification to actually transforming sound for the hearing impaired and deaf, making cochlear implantation a landmark medical achievement. He then outlines their more existential aid in enabling the hearer to reconnect with his or her identity, as hearing loss also brings with it a disconnect to self.

Nonetheless, the new technology has spurred criticism, the first major wave of which came from ardent spokespersons of Deaf culture, even branding the device and its aim as a form of "genocide." (One is reminded of the initially sparked critique of feminism in the U.S. by women's groups such as AWARE, American Women Already Richly Endowed.) According to the more radical Deaf culture critique, assuming hearing culture as "normal" devalues the non-hearing. This 
critique, however, further polarizes the debate as issues are framed within the context of 'ethical dilemmas.' In laying all this out, Kermit rightfully worries that excessive focus on the technology itself of cochlear implantation as 'the problem' perpetuates the line-drawing: either for or against. More significantly, however, there is cause for real concern in that both sides assume a common, though questionable, telos, namely the aim of bringing about children who can hear and speak.

Kermit sensibly suggests we reframe the question so that the issue lies not simply in whether or not we use the technology, but in considering the wider context in which we act, what is involved in the rehabilitative process, and what long-range social consequences does all this bring about? First, cochlear implants do not simply consist in the procedure of implantation itself, but in its follow-through and consequences. That is, cochlear implants are not simply events, but protracted processes. Along these lines, as a second consideration, though we ordinarily think of technology as a specific technique applied to a specific situation, he suggests we rethink the idea of "technology" to include wider contexts of its application. That is, technology also comprises a technique's originating, current, and ensuing contexts and outcomes, thus giving added weight to the meaningfulness of cochlear implant's process of rehabilitation.

He advises a moderate, prudent, and measured framework. This nicely illustrates the vital significance of how we frame the question-not simplistically as either/or, but artfully as bundled within a complex social and cultural context. Again, the notion of telos resurfaces. What is the ultimate aim of cochlear implantation? If, as is currently touted by proponents, the foremost aim is to enable speaking, considered the normal and sought modality, is this a realistic aim? Is it a fair aim?

Aptly, Kermit embarks upon an extended discussion of the normative implications of the notions "normal" and "abnormal." If "rehabilitation" signifies "to make fit again," as he puts it, there are subtle evaluative assumptions having to do with "fitting" into the prevailing culture which communicates through speaking. For Kermit, all this must be weighed against the pivotal question: What is truly in the child's best interest? Kermit underscores here the ethical imperative of recognizing the intrinsic worth of each child instead of placing more value on those children who have provided more rote evidence of speaking proficiency. Furthermore, in view of the misguided assumption that speaking is the principal aim in rehabilitating those with cochlear implants, what does it mean to learn a language? As those of us know from language studies, knowing a language extends far beyond mere technical facility and includes grasping symbols, cues, and contexts. Though moderates claim that sign language cannot sufficiently replace speaking, Norway's encouragement and emphasis upon the value of bilingual education for the hearing impaired-sign and spoken languages-illustrates a more balanced approach to the issue, reinstating the value of sign language on a par with speaking.

Kermit urges attending to the rehabilitation process itself so that best interests of children are surely inclusive of personal development along cognitive, social, and moral lines, not simply speaking "proficiency." These extend beyond biomedical concerns. In this respect, he raises a question we need to more properly address: In bioethics, how far does our moral responsibility extend? Within biomedical 
confines? Do we leave other matters-social, cultural, educational—to others? Much hinges upon how we define this technology's telos.

In our final essay, Darryl Macer thoughtfully explores cultural worldviews through his summary of the general Asian acceptance of enhancement-particularly in China, India, and Thailand. In doing so, he lays out ethical challenges this incurs in view of longstanding cultural values emphasizing social well-being over individual interests, challenges that include the human-nature relationship, views of self, and matters of social justice. Enhancement technologies especially generate an ontological imperative, having us question what it means to be human. And with our potential to engineer our existence, are there limits to self-reconstruction? With this in mind, he inquires as to how we can ethically assess this general acceptance in Asia.

His extensive 1993 International Bioethics Survey clearly reveals positive views of genetic enhancement. For example, around $75 \%$ of those surveyed favorably viewed personal use of gene therapy. Regarding Chinese perspectives, the term Yousheng, "healthy birth," can be compared to "eugenics," or "good in birth." At the same time, the IBS study unveils diversity among Asians. Not all are of one cloth, with apparent disapproval in Japan, Australia, and New Zealand, along with Thailand's general disfavor of gene therapy on grounds that it is unnatural.

Asia now seems to be at a turning point as, in Macer's view, countries' "bioethical maturity" enables them to more reasonably assess benefits and harms of the new eugenics, or genetic enhancement. Enhancement extends into other areas like education (Matt Lamkin's focus) and hearing (Patrick Kermit's concern). Enhancement also involves issues of appearance, such as dental and facial aesthetics and having whiter skin through whitening creams. This speaks volumes regarding our increasingly image-conscious global society. There is no denying the dominant influence of Western culture in the magnetic power of images in shaping views of identity. For instance, with increasing pressures placed upon body image, blepharoplasty and rhinoplasty have become more popular in the Republic of Korea, Thailand, Taiwan, and Japan. Moreover, the relatively lower costs for these procedures in Asian countries generate escalating enhancement tourism from Westerners.

Given rich traditions that generally resist overemphasis on individual freedoms, is all this ethically warranted? Macer rightfully poses the plaguing question of universality, particularly in a world increasingly touted as diverse, through contrasting Western Abrahamic and post-Enlightenment emphasis on objectivity of principles versus an Indic tradition's more subjective approach towards moral principles. At the same time, critical features in Western ethical theory find an earlier voice in traditional Asian accounts, such as Mo Tzu's utilitarianism, sustained also in the vital value placed upon harmony. Given all this, we cannot avoid the vital question of telos - what is the final aim and highest good?

Macer cautions us to avoid casting monolithic nets over cultures. All cultures are inherently diverse. Nonetheless, deep-rooted Asian traditions and teachings, as in Buddhism and Confucianism, tend to underscore two interrelated beliefs. First, that we consider long-term consequences of our decisions and actions. Second, that we assign priority to the well-being of the common good over individual, private 
interests. However, as in the case of gene therapy, stronger waves of individualism appear evident. To illustrate, while Buddhism emphasizes selflessness, particularly through the challenging idea that the individual self is a dangerous illusion, growing interest in reducing family size and maintaining gender selectivity illustrates growing evidence of self-interest bordering on self-centeredness. Mounting materialism is another symptom of self-centeredness.

While notions of human dignity are not doubt supported in international documents on human rights, like UNESCO's Universal Declaration on the Human Genome and Human Rights, its two distinct covenants, the International Covenant on Economic, Social and Cultural Rights emphasizing social and communal welfare and the International Covenant on Civil and Political Rights stressing individual freedom of expression, show how welfare-based, socialist premises conflict with individualist-driven, capitalist models, adding weight to arguments against a universality of moral values. And, along with Sandra Shapshay, Macer poses questions regarding human reproductive cloning in the matter of human rights.

Macer discusses how underscoring autonomy unearths conflicts within the historical context of Asian philosophies emphasizing the primacy of the group and interconnectedness, a core teaching in Buddhism. Environmental issues naturally enter in as all this gives rise to tensions among matters of self-interest, otherinterest, group-interest, species-interest, and Nature-interest. Likewise, Confucian teachings, ethically bound rather than metaphysically-grounded underscore a relational ethics and harmony with humans and nature. Varieties of enhancement pose a challenge to these traditions.

Given these tensions, policies banning enhancement technologies in Asia appear naïve. Not only would such a ban be ineffective, but once the ban is likely breached, this sets incentives for various forms of upgrading and competition. Despite the longstanding emphasis upon considering long-term social impact of individual decisions, people everywhere, including Asians, seem increasingly compelled to make their own choices, regardless of international legal barriers. Rather than prohibitive policies, it makes betters sense to insist upon extensive education in order to ensure more sufficiently informed consent with respect to enhancement technologies.

In summary, our contributors have offered instructive and enlightening essays on highly complex issues. Their questions and challenges are far-reaching. They show how questions of telos and culture are interrelated. And in view of their proposals, whatever reactions and comments readers may have, they cannot charge our contributors with any lack of ambition as to their respective claims. When formed by thoughtful scholarship, sound evidence, and in-depth reflection, their views demand that we take seriously their insights and proposals. 